Roth. W.-M., Mavin, T. J., \& Dekker, S. W. A. (in press). The theorypractice gap: Epistemology, identity, and education. Education \& Training.

\title{
The Theory-Practice Gap: Epistemology, Identity, and Education
}

The question whether there is truth to human thinking is not a question of theory but a practical question. In practice man has to prove the truth, that is, the reality and power, the this-sidedness of his thinking. The debate over the truth or non-truth of thinking, which isolates itself from practice, is a purely scholastic question. (Marx/Engels, 1958, p. 533)

Practitioners of all sorts-including nursing (e.g., Ekebergh et al., 2004; Nematollahi \& Isaac, 2012), non-profit management (e.g., Donmoyer et al., 2012), clinical medical practice (e.g., Brown, 2012), and midwifery (Doughty et al., 2007)talk about the gap that they experience between what they do and learn in school, college, or university, on the one hand, and what they do and learn while working (practice), on the other hand. Practitioners' talk about a gap between theory and practice is not just a question of mere language: it is frozen into, and embodied by, societal divisions of labor and institutions (Allen, 2011). This state is the result of historical developments, whereby the scholastics (schoolmen) not only asserted the separation of practical knowledge from theoretical knowledge-Bourdieu (2000) uses the term scholastic epistemocentrism-but also privileged the latter over the former (Marx/Engels, 1958; Ricœur, 1992). The differentiation between theory and practice actually goes back to Aristotle, who distinguished (a) theoria, characterized by self-sufficient contemplation (b) from (political, war) praxis, involving actions that have goals other then themselves and bring about change in the world (Aristotle, 1934). This opposition was retained by Marx and Marxist thinkers, who contrast (self-sufficient) philosophical contemplation and political praxis that changes the world (Lukács, 1971; Marx/Engels 1958). In a "hierarchy of units of praxis," "the first composite units are those deserving the name of practices" (Ricœur, 1992, p. 153). The term practice refers to a sequence of patterned actions as these are typical of professions, the arts, and games (practices). Thus, in a strong sense maintained here, even the most theoretical or esoteric fields such as pure mathematics or theoretical particle physics constitute practices (Livingston, 1986; Merz and Knorr-Cetina, 1997).

Whereas in traditional societies the predominant teaching-learning mode is apprenticeship, a division of labor exists in industrialized nations between formal educational institutions and the work world (Goody, 1989). Embodying the scholastic focus on knowledge, modern educational institutions emphasize theory and decontextualized practical skills. Knowing-of-practice tends to take precedence over knowing-in-practice (Lave, 1996). Knowing-in-practice, however, requires not only knowing-that and knowing-how (i.e., skills, techne) but also knowing-what-for and knowing-in-order-to (Heidegger, 1977; Roth, 2010). For example, teachers or electricians embark on (university- or college-based) coursework, where they come to know the epistemic essence of their professions and then-during practicum or apprenticeship—are asked to apply what they have learned and thereby overcome 
the theory-practice gap (e.g., O’Flaherty et al., 2011). But time and again-in our research with teachers, seafarers, electricians, scientists, fish-culturists, or pilotspractitioners themselves tell us about the gap between coursework and the real sensual work that they actually do at the job site. Evaluation methods also reflect this gap, as there are differences between (a) the competencies required to be successful on an (paper-and-pencil, computer-administrated) examination designed to test the presence of knowledge or practical tests and (b) the at-work competencies that are required for a job well done.

The purpose of this paper is to contribute to our understanding of the theorypractice gap as experienced and articulated by practitioners, to theorize the origin of this gap and, in so doing, show that it is an artifact of the underlying epistemology (epistemologies) reified in institutional practices of education and training. We begin with two vignettes derived from two multiyear ethnographic studies. In these studies, practitioners extensively talked about a gap that they experienced between college (theory) and work (practice). Using these concrete cases as exemplifying materials, we then present cultural-historical activity theory as a way of understanding the gap. The theory, though it is itself not binary but highlights the relation between consciousness and forms of activity, allows us to understand why practitioners dichotomize work and school in the way they do. We then move to show that in aviation we can find alternative approaches to education and training, supervision, in-service training, and (personnel) evaluation that lead to more integrated experiences. In contrast to other industries, training and evaluation are enacted in ways that integrate formal theory into practice after practitioners have had relevant experiences. The implications present examples of training models where theory follows and is grounded in practice rather than preceding practice.

\section{The Relation of Theory and Practice in (Institutional) Practice}

To exemplify the nature and source of the theory-practice gap, the results of two multi-year ethnographic studies are presented. The gap exists not as the result of theorizing what people do (i.e., ideally) but exists practically: it is experienced and thematized by practitioners. These studies therefore document the distinction between knowledge as treated at college and as it is relevant in the real workplace for which the former was to prepare students.

\section{Seafarers: Between Practice and College}

In the maritime domain, the prominence of disasters has led to the creation of an international certification system (Emad and Roth, 2009). The Standard of Training, Certification and Watchkeeping for Seafarers 1995 emphasizes competency-based education and training. Thus, ship officers should be able to demonstrate the competencies listed and described in international convention. Although the conventions anticipate a combination, interaction, and integration of (collegebased) education and training plus practical experience on-board ship, the actual institutional practices do not achieve such integration. Thus, when ship officers interested in upgrading their certification arrive at the college, the courses they have to take do not draw on the expertise that they developed by being part of ship 
personnel. The knowledge-in-practice (Cochran-Smith and Lytle, 1999) pertinent to the former and future positions held, was experienced as bearing little relevance to what was required for being successful in college. In fact, ships officers and their college instructors knew that what was to be studied and the tests that would certify relevant knowing-that bore little relation to the actual work that the officers have done or will be doing. That is, these courses do not-and cannot as culturalhistorical activity theory will suggest-provide contexts in which the what-for and in-order-to relations typical of practice exist. Our research shows that instructors and students colluded in assuring that (a) the latter would successfully complete their courses and examinations that implemented the national version of the international Standard of Training, Certification and Watchkeeping for Seafarers 1995 and (b) students received the sought-after certificate. Instructors and students were relatively little concerned with the question whether what was learned actually bears on practice. The one exception was the course in which the seafarers worked with simulated electronic navigation systems. Not only did the seafarers understand that their knowing-how (competencies) to operate the electronic navigation system is required onboard but also they felt "more confident, prepared, and competent to do what is required of them on-board ship" (Emad and Roth, 2008, p. 266).

One might assume that the on-board component is deemed more relevant to the knowing-how required by the positions that seafarers hold after completing the training (e.g., as Chief Mate, Master, or Watchkeeping Mate). However, despite the potential that on-the-job training offers, it was shown "that in practice it is not taken seriously by most of the ships' staff and students and, as a result, the learning outcomes are unpredictable" (p. 266). There was not only a lack of (college) supervision but also a lack of coordination between the goals of the college responsible for the training on the one hand, and the ship officers and shipping companies on the other. Moreover, the lack of supervision led to the absence of evaluation: certification meant simple on-board presence without guaranteeing any expansion of the knowing-how of the students. Even though work placement can lead to higher achievement (e.g., Patel et al., 2012), Emad and Roth (2008) concluded that for the mariners involved college training "does not close the existing gap between what is learned and what is needed on the job" (p. 266).

\section{Electricians: Between College and Apprenticeship}

A three-year autoethnographic study investigated the education and training of electricians in a program that required individuals to take college courses and to apprentice on real job sites (Racca, 2003). In the education and training of electricians, the gap between theory and practice manifests itself and is produced in the institutional separation between the learning of facts and theory (knowing-that) in college courses and the learning of the skills (knowing-how) on the job. This gap-that electricians talk about in school and at work-mediates how they articulate their identities. The experienced gap between theory and practice is an integral feature of becoming an electrician. First, they feel that there is a separation between knowing-how and knowing-that is required for successful completion of college-based courses. For example, the national (Canadian) and provincial 
standards ("Codes") determine the nature of the bends that can be made in the electrical conduits that encase otherwise exposed electrical wire. The angles, offsets, and distances involved in making bends can be calculated using trigonometry (theory); they can also be made following practical rules (Roth, 2012). Thus, in college have electricians in training must learn and use trigonometry to calculate the bending of a metal conduit for electrical wires. The instructors consider this knowledge to be important because the conduit is to be placed in/as one piece so that the shortening that occurs when it is bent to circumvent some obstacle has to be figured out before actually cutting the conduit. Many students enrolled in the electrician program find trigonometry difficult. At work, electricians do not employ trigonometry but use a bender. In the three years of the study, including 4 different worksites, not even one electrician calculated angles. The bender allows electricians to fashion conduit pipe without ever doing trigonometry. The required trigonometric knowledge is crystalized in the marks and numbers found on the tool and in the shape of the tool. Journeyman electricians tell apprentices that their college lessons differ from what they really do at work.[1] That is, journeymen do talk about the knowing-that required for college and use it to actively produce the gap between theory and practice in and through their talk. The competency to talk about the gap is as much a part of becoming a licensed electrician as the actual calculations and on-the-job practice of bending (Roth, 2012). However, the college form of knowing-that and knowing-how actually would be required if electricians had to account for what they have done in the case of an inspection or in the case of an accident caused by wiring-cases in which the electricians would be held to the electrical code of the jurisdiction. The stories about the gap, therefore, are (a) occasioned by a really experienced gap between (college) theory and (work) practice and (b) an integral aspect of the production of this gap.

\section{The Relation of Theory and Practice in (Cultural-Historical Activity) Theory}

[This understanding of history] does not explain praxis out of ideas, explains the formation of ideas out of practice. (Marx/Engels, 1958, p. 38)

There is a wide acceptance of a gap between theory and practice not only among practitioners but also among theoreticians. This is shown in such concepts as third space, where the practices two cultures are cobbled together (Moje, 2004), or boundary crossing, where learners are confronted with the different practices in school and at work (e.g., Engeström, 2000; Tsui and Law, 2007). Although there are other attempts to theorize and overcome the theory-practice gap-e.g., social practice theory (Bourdieu, 2000; Lave, 1996) or the theory of reflective practice (Schön, 1983)-cultural-historical activity theory is especially suited to do so (though not necessarily contradicting the former). What is common to the theories is that they accept the introductory quotation to understand practice as the locus where competencies and ideas are created-it is the locus of knowledge-in-practice (Cochran-Smyth and Lytle, 1999). In contrast to other approaches, culturalhistorical activity theory affords understanding the theory-practice gap in the context of a more comprehensive theory of society, understood as a network of 
productive activities (Jahreie, 2012; Roth and Lee, 2007). The minimum analytic unit that includes all the characteristics of society is (productive) activity, represented in its structural dimensions in Figure 1.

Cultural-historical activity theory, now in its third generation (Roth, 2007a), is the result of an attempt to create a concrete human psychology (e.g., Leont'ev, 1983; Vygotskij, 2005; Vygotsky, 1927/1997) based on explicit Marxist ideas about understanding human activities practically rather than ideally (Marx/Engels, 1961). It is a holistic theory of human activity, consciousness, and personality that takes collective activity, the real production and satisfaction of generalized needs as its fundamental units of analysis (Roth, 2013). Thus, electrically wiring buildings is a typical productive activity, which, beginning with wires, solder, conduits, wire nuts and a variety of other raw materials (Figure 1a, objects), produces a completely wired building (Figure 1a, outcome). Being exchanged with other activity systems, the finished product becomes part of the latter: this constitutes the what-for and inorder-to dimensions of practice. For example, wired houses are necessary (in industrialized nations) to satisfy the need for light and energy for cooking (consumption in and by society, Figure 1a). How the production process unfolds depends on the means of production-e.g., whether the electrician uses an electrical bender, a hand bender, or a makeshift bender (filling conduit with sand to prevent crimping and bending it around something). These means leave their traces in the final product (e.g., a makeshift-bent conduit will differ from one electrically produced). As a result of the existing mediations, the category activity captures the (societally, materially) situated and distributed nature of ongoing practice and the cognition (consciousness) that goes therewith. That is, rather than dichotomizing practices, cultural-historical activity theory suggests that there are as many forms of consciousness as there are society-constituting human activities (e.g., Roth, 2004).

\section{««««" Insert Figure 1 about here »"»"»»}

In cultural-historical activity theory, the object/motive (Figure 1a) is a key feature. This feature captures the changes productive activity (praxis) brings about in the world - an idea central to Marx's theory of praxis (i.e., "Philosophers only interpreted the world differently; the point is to change it," Marx/Engels, 1958, p. 535). This is so because the term object not only refers to the raw materials (e.g., the wires, trays, conduits of the electrician) but also to the anticipated outcome (e.g., the finished wiring project). This outcome initially exists only at the ideal level (e.g., in the building plan, as idea). It does so until the product has been completely realized in a concrete fashion. The object therefore also constitutes the motive of activity: It exists twice, once at the material, once at the ideal level (Leont'ev, 1983; Roth, 2013). The object/motive embodies the what-for and in-order-to orientation of the activity. It distinguishes one activity from another; and it distinguishes the characteristic forms of consciousness. On the job, electricians do not just bend conduit for fun; they bend conduit to get a job done quickly and economically. Thus, whereas it does not matter in college how many pieces of conduit are bent until the student has completed it to the satisfaction of the instructor (failures are discarded), on the job no conduit must be wasted for doing so decreases the earnings of the company (Roth, 2012). The object/motive is also that moment of activity that marks the temporal dehiscence of the fundamental unit of analysis. Thus, the entire job of 
wiring a building from the beginning to the end would be captured by the category activity (Figure 1a). It is therefore not only the object/motive that exists twice: the entire activity involves material practice and its ideal reflection in consciousness.

Because of how activity is framed as the minimum unit, the theory also integrates over the goal-oriented concrete actions of individual subjects that realize an activity and over the conditioned (unconscious) operations that constitute each action. Cultural-historical activity theory predicts differences in actions and operations even though a task might surficially appear to be identical-e.g., the bending of electrical conduit in college and at work or working on-board as part of practicum versus doing the real job. This is so because the sense of an action is a function of the nature of productive activity. Thus, the purpose of bending a conduit is very different within the activity of schooling than it is when completing a job on site, and the completion of the practicum for the purpose of certification is different from doing and being responsible for a task on a real ship. This is because of the differences in the structure of the activity systems (Figure 1a) and because the societal relations are very different. Because consciousness and personality are understood as the totality of societal relations, very different higher psychological functions are the result of participating in one versus another activity (Leont'ev, 1983; Vygotskij, 2005).

Within cultural-historical activity theory, learning is thought differently than in other epistemologies (e.g., information processing or constructivism). First, rather than locating learning in the individual brain-i.e., as acquisition or construction of factual and procedural knowledge (skills, schema) - cultural-historical activity theorists locate learning in the physical relations between people (Leont'ev, 1983; Vygotskij, 2005). Thus, "any higher order psychological function was external; this means that it was social ... the relation between higher psychological functions was at one time a real/material relation between people" (Vygotskij, 2005, p. 1021, original emphasis). That is, what is a real/material relation within productive activity one day is the relation between higher functions on another day. In college, the relations are between instructors and students; at work, the relations are among practitioners and with superiors; and in all other activities in which an individual participates, these relations are again different. Very different forms of knowing and learning processes are the result-being told theory versus learning at the elbow of another. Second, in the process of material production, the (human) subjects of activity are transformed on two levels: physically (people get better at doing what the job requires) and ideally (the activity is reflected differently in consciousness). In fact, because of the fundamental unit of analysis is spread across time (Figure 1b), change and learning are implicit and inherent in the theory. As the activity unfolds, no only does the world change but also so do the agents (Marx/Engels, 1958; Leont'ev, 1983). Participating is learning-in-practice (Lave, 1993). All of these aspects lead to the fact that in cultural-historical activity theory, the motive is part of knowing-in-practice (i.e., its what-for and in-order-to orientations). Knowing-how to do something always implies specific and pertinent knowing-that, a situation denoted by the term theory-in-use in other practice theories (e.g., Argyris and Schön, 1974). In different professions, there are different forms of knowing-in-practice. Thus, pool players are oriented towards winning: they read the situation on the 
table, use the queue to play the ball, and down it in one of the pockets. Physicists or mathematicians, on the other hand are oriented towards theoretical issues and publications: they use models to calculate the trajectory of the ball. Playing pool and doing physics, though both might be concerned with the trajectory of the ball, are experienced as very different activities, implying very different practices, objects, tools, and outcomes-and, therefore, very different forms of material practice and (ideal) consciousness (knowing-how, knowing-that). From the cultural-historical activity theoretic perspective, there is no gap between theory and practice, because within physics and playing pool, knowing-how and knowing-that are enacted simultaneously and no assumption is being made about the pertinence of knowingthat/how in physics and knowing-that/how in professional pool. Thus, even the most theoretical of fields still constitute fields of material practice.

\section{Training and Evaluation in the Airline Industry}

The studies from the training and certification of seafarers show how students (seafarers) and college personnel (instructors) colluded to deal with the institutionally embodied, really experienced gap across the divide of college (including practicum) and workplace. The studies from the training of electrician show that the experienced gap not only is immanent in the division of labor between college-based education/training and workplace but also contributes to the production of this distinction. The preceding section presents a theoretical framework that allows understanding why practitioners experience such gaps. In an epistemology of practice (e.g., Bourdieu, 2000), even the most theoretical of disciplines are understood in terms of human practice that manifests itself simultaneously in material and ideal form and as knowing-that and knowing-how. In some industries, the needs of the workplace have led to the development of approaches in training that no longer embody those epistemologies that make the distinction between theory and practice. In the airline industry, where a crew practicing emergencies in a real aircraft could and have had disastrous effects, it may not be surprising, therefore, that companies spend some of their resources purchasing simulators that are used for training and evaluating pilots (Mavin and Murray, 2010). By employing the same means across traditionally distinct activities - (a) education and training and (b) work and performance assessmentone airline company participating in our research narrows the gap that many of its pilots have experienced in the past. In this section we provide a case description followed by an analysis grounded in cultural-historical activity theory.

\section{Case Description}

The airline company hires pilots and then provides them with the type-rating training required to fly the specific aircraft type it employs. Type-rating training typically takes 11 four-hour sessions in a simulator that replicates the cockpit of the aircraft type. During type endorsement, pilots fly under simulated conditions into the various airports that the company services. The simulator can replicate any kind of weather, turbulence, time of day, location, and emergency; and the simulator can be immediately reset to provide pilots with multiple attempts until they exhibit a desired proficiency level. The fidelity of the simulators today is so high that some 
companies, such as the airline we study, trust the validity of the training to be sufficiently advanced to allow a new pilot to fly a real aircraft with passengers on their first time out. On completion of a type rating, a further four weeks of real aircraft flying with passengers will occur prior to final evaluation. However, even pilots, who are now flying with the company as operational pilots, continue to revisit the simulator every six months, for the remainder of their career, to have their proficiency evaluated. This evaluation is a substitute for assessing continued quality performance on the job as required in this high-risk activity. Whether such evaluation leads to an increase in knowledge-of-practice (Cochran-Smith and Lytle, 1999 ) is not known at the present time.

A flight examiner, who sits at the instructor station behind the two pilots, conducts the training and evaluation session. Typically, the examiner takes notes during training and has an evaluation metric (Table 1). A camera records the session. The recorded video functions as a debriefing tool. It allows participants to reproduce entire or selected sections back in the debriefing room. The debriefing session engages participants in video-based reflection on practice, which has shown to lead to knowledge-of-practice (Roth, 2007b; Zhang et al., 2011). Both the evaluation metric and the recording subsequently are used to debrief, where examiners replay pertinent situations that are chosen for the purpose of learning from it. According to examiners, “debriefing tool shows, people don't realise how they communicate. Until you sit there and watch yourself on a video, you don't realise how you act and speak and that, these sorts of things" (120525-3: 55). Even when the examiner simply plays part of the recording, pilots often "figure it out and they can see what happened themselves and figure out why it happened" (1205253: 56).

\section{««««" Insert Table 1 about here "»»»»"»}

In the past, a pilot's proficiency, both in the simulator and aircraft, was centered on flying skills and aviation knowledge. However, history showed that the "soft skills" (including decision-making, teamwork, and communication) played a significant part in aircraft accidents (Mavin and Murray, 2010). To reduce or eliminate this problem, crew resource management training was implemented. Crew resource management training was often of the "talking-head type." As one pilot noted, "lots and lots of models, graphs and diagrams, this doesn't work for me and I don't believe it works for my students when I'm instructing [crew resource management] either. Some of the graphs and models that I've used over the last few years confuse even me, the facilitator" (120524-2: 49). That is, the pilots found it difficult to relate the knowing-that taught during the crew resource management training courses to knowing-how of their everyday work-e.g., they found it difficult to hear about communication and to improve communicative practices. The company then changed its approach to provide a new, practice-oriented training. During their crew resource management training courses, pilots now rate the performance of peers viewed on specially prepared training videos (see Table 2 for a typical scenario). The pilots use an assessment metric that was the result of an industry-university collaboration and is based on a holistic model of pilot performance. The model itself was the result of a grounded theory approach (Corbin and Strauss, 2008) used to analyze interviews with flight examiners, that is, it was 
directly grounded in the knowledge-of-practice. This model integrates "hard" technical and "soft" non-technical skills required for the safe completion of a flight (Figure 2). In this context, the pilots actually come to develop the evaluation-related knowing-how because they themselves evaluate peers; and in so doing, they also learn more about their own performances, especially when they recognize in the observed performance something that they themselves do, but now critique as less than perfect performance. For example, one pilot noted, after having seen a training video in which the pilot provide a mono-syllabic response: "I now know that the next time I give a one word answer I want to quickly reflect on what I've just answered, because it might have been something really important" (120524-2: 51).

\section{««"«« Insert Table 2 about here "»»»»"» ««««« Insert Figure 2 about here »»»»»»}

\section{Analysis - The Perspective from Cultural-Historical Activity Theory}

To achieve high-level pilot performance, airlines increasingly move to bridge the gap that exists between two, traditionally distinct activities: (a) taking crew resource management courses and examinations and (b) flying a plane as part of the job. In cultural-historical activity theoretic terms, these two situations were part of different forms of activity and, therefore, involved different forms of consciousness. It has been suggested that the two activities can be arranged so that they become complementary (Roth et al., 2002) or dialectically related when one activity (work practice) becomes the object/motive of the other (Roth, 2005). Our airline company works towards the sought-after integration by situating type-rating training, crew resource management training, and evaluation in the workplace situation or in simulators where the pilots work under nearly the same conditions. In the simulator, the pilots are confronted with the same equipment and assessment tools (means), division of labor, object/motive, and rules that also characterize their normal flights. That is, their work on the simulator requires the same forms of consciousness (knowing-that) that a real flight requires. The use of a practice-based theoretical model and an associated assessment metric further introduces formal knowledge-of-practice into knowledge-in-practice. Any assessment, therefore, is ecologically valid; and there are serious consequences if a pilot fails the evaluation.

Learning arises from practice itself: pilots learn to fly by flying (on the simulator) rather than by studying a book and then applying it in the cockpit. This is especially the case for the "soft," non-technical skills of the crew resource management. The debriefing tool is an activity theoretic means that replays pertinent parts of a simulator session. The tool affords reflection-on-action, and, with it, the generation of knowledge-of-practice (Roth, 2007b; Zhang et al., 2011). The research-based model and the assessment metric, having arisen from practice, embed now-formal theory in work practice-the model and evaluation matrix become means in the activity system (Figure 1a). This does not close the theory-practice gap: because, in watching themselves, the pilots cross, to paraphrase Bourdieu (2000, p.52), the "inevitable boundary" between the world in which they think and the world in which they live. Thus, even and precisely in the case of high-fidelity, "photorealistic" simulators, the resilience required to deal with the nearly infinite variations in and of practice may not only lack in pilot training but also be actively 
taken out of it (Dahlström et al., 2009). However, the crew resource management courses use the same means (model, assessment metric) that examiners employ and that pilots experience as part of their assessment. The gap between (a) education and training and (b) practice is narrowed. In fact, as some pilots become examiners themselves, learning to use the model and assessment metric is part of their career trajectory. Dahlström et al. (2009) note that mid-fidelity training situations may actually increase the validity of the training. Cultural-historical activity theory again allows us to understand this situation, because the object/motive of training is different of the object/motive of everyday practice and, therefore, inherently entails different forms of consciousness (including the always-present affective component).

Time on the simulator is expensive. The alternative of having pilots evaluate other pilots doing their job affords them to know the performance model and the associated assessment metric in and through the practice of working with these tools (means, Figure 1a). Watching the videos provides pilots with learning opportunities: they see their own practices in the behavior of others and, thereby, beginning to change them. Seeing the video and discussing them with peers, though decreasing the fidelity of the training, may be one of those instances where discussions are fostered that increase the ecological validity of the training situation (e.g., Dahlström et al., 2009). A second advantage of these video evaluation sessions is that the pilots develop analytic skills that assist them during the debriefing sessions after their bi-annual evaluations. Even here, learning to assess pilot performance (their own, that of others) is achieved by assessing pilot performances (others', their own). In fact, some of the pilots eventually become flight examiners themselves, and, for the company, are responsible for assessing the performances of their more junior peers. Pilot performance assessment becomes part of the career trajectory of (some) pilots, in the same way as being a first officer prior to serving as captain, and just as moving through the different position on the bridge of navy vessels (Hutchins, 1995).

\section{Addressing the Scholastic Theory-Practice Separation}

The purpose of this paper is to conceptualize the origin of the theory-practice gap that practitioners in many field experience between their education and training, on the one hand, and the workplace, on the other hand. At issue is not an abstracted distinction between knowing-that (factual and procedural knowledge) and knowing-how (skills, procedural knowledge applied), but rather, as the First Thesis on Feuerbach states, one of understanding human actions as praxis, the real sensual engagement with the world (Marx/Engels, 1958). Taking as its starting point the Feuerbach theses, cultural-historical activity theory allows us to understand why there would be a difference, for it makes thematic not only that the knowing-that/how differs across activity systems but also that practical activity has to be understood from the perspective of praxis (Leont'ev, 1983). The gap exists even in training systems with very high fidelity, such as aircraft simulators, because an overemphasis on technical skills, rules, and procedures tends to decrease the resilience required to deal with real, unexpected events and problems that might be 
resolved only when practitioners (e.g., crew on a vessel) step outside the box (Bergström et al., 2009). As our introductory examples show, the object/motive of formal education/training is to pass examinations and receive certification, which is different from the object/motive of the profession (e.g., transporting people and goods, wiring a building). The gap between knowing-that and knowing-how is actually embodied in the societal division of labor between education/training and work, anchored in stable institutions. Cultural-historical activity theory allows us to understand that even placement and practicum experiences, when conducted in the context of formal education, are part of the system of schooling and, therefore, involve different forms of knowing-that/how than being integral part of the job. This is so because of the different forms of division of labor, rules (evaluation), object/motives (students work knowing they are assessed by supervisors), and so on. Practice theorists, taking the same stance as cultural-historical activity theorists, warn that the aim of science should not be "to adopt practical logic for itself, but to reconstruct that knowledge theoretically by including in the theory the distance between practical logic and theoretical logic" (Bourdieu, 2000, p.52). How might this be addressed institutionally?

The specific ways in which institutions can change from a scholastic approach to education and training of practitioners (i.e., separation of theory and practice, theory prior to practice) to a practice-based approach depends on the profession. The example from the aviation industry exemplifies the possibility of aligning education/training and assessment with work practice. Other studies in a variety of activities have shown that reflection on practice, in which practice is made visible and theorized, conducted as part of work practice affords learning in terms of what we call here knowledge-in-practice and knowledge-of-practice (e.g., Engeström et al., 1996; Noss and Hoyles, 1996). The bi-annual evaluation provides proof that pilots enact relevant technical and non-technical skills. Alignment, however, does not mean complete removal of the gap even under photo-realistic simulation conditions (e.g., Dahlström et al., 2009). However, some institutional arrangements have been made to co-locate education/training and everyday practice. For example, in the education of science teachers, the feasibility to take a completely practice-based approach has been shown. Thus, at the University of Pennsylvania, science teacher education was at one time based on the \{coteaching | cogenerative dialoguing model\} (Roth and Tobin, 2002). In this model, those interested in being certified as teachers-graduates of some science program who already had work experience in a profession-would learn to teach by teaching at the elbow of another. They would learn to talk about their practice using relevant theory in courses where it was formally introduced in the context of problems arising from practice. In this approach to teacher enhancement, theory follows and is based on practice (knowledge-in-practice) rather than the other way around, an organization that also underlies the structure of this paper. Studies using this model show that all participant stakeholders learn-i.e., develop (knowledge-of-practice (CochranSmith and Lytle, 1999) - both knowing-that (e.g., specific biological facts and theories) and knowing-how (e.g., how to teach biological facts and theories); and these forms arise from participating in the praxis of teaching where knowledge-inpractice comes to bear and is developed (e.g., Roth et al., 2002). Whereas the 
feasibility of this approach has been proven for teacher education, it remains an empirical matter whether the approach is transferable to other practices. To a great extent, this requires that the formal learning institutions loosen the grip that their scholastic approach to knowledge has had and continues to have over the question of the theory-practice relation.

\section{Note}

[1] In the traditional trades, the career trajectory of a practitioner includes three stages: apprentice, journeyman, and master (Goody, 1989). Apprentices learn the trade by working with, and at the elbow of, experienced practitioners (journeymen and masters). In industrialized societies, apprentices generally receive a small wage. In traditional societies, the often have to pay (e.g., Coy, 1989). Journeymen are licensed but tend to work for someone else. Masters tended to have their own business.

\section{References}

Allen, J.M. (2011), "How front-end loading contributes to creating and sustaining the theory-practice gap in higher education programs", Asia Pacific Education Review, Vol. 12 No 2, pp.289-99.

Argyris, C. and Schön, D.A. (1974) Theory in Practice: Increasing Professional Effectiveness, Jossey-Bass, San Francisco, CA.

Aristotle (1934). Nichomachean Ethics (H. Rackham, trans.), Harvard University Press, Cambridge, MA.

Bergström, J., Dahlström, N., van Winsen, R., Lützhöft, M., Dekker, S. and Nyce, J. (2009), "Rule- and role-retreat: An empirical study of procedures and resilience", Journal of Maritime Research, Vol. 6 No. 1, pp.75-95.

Bourdieu, P. (2000), Pascalian Meditations, Stanford University Press, Stanford, CA.

Brown, J. (2012), "Clinical communication education in the United Kingdom: Some fresh insights", Academic Medicine, Vol. 87 No.8, pp.1101-4.

Cochran-Smith, M. and Lytle, S. (1999), "Relationships of knowledge and practice: Teacher learning in communities", Review of Research in Education, Vol. 24, pp.249-305.

Corbin, J. and Strauss, A. (2008), Basics of Qualitative Research: Grounded Theory Procedures and Techniques, Sage, Thousand Oaks, CA.

Coy, M. (1989), "Being what we pretend to be: The usefulness of apprenticeship as a field method", in Coy, M.W. (Ed.), Apprenticeship: From Theory to Method and Back Again, State University of New York Press, Albany, NY, pp.115-35.

Dahlström, N., Dekker, S., van Winsen, R. and Nyce, J. (2009), "Fidelity and validity of simulator training”, Theoretical Issues in Ergonomics Science, Vol. 10 No.4, pp.305-14.

Donmoyer, R., Libby, P., McDonald, M. and Deltrick, L. (2012), "Bridging the theorypractice gap in a nonprofit and philanthropic studies master's degree program", Nonprofit Management \& Leadership, Vol. 23 No.1, pp.93-104.

Doughty, R., Harris, T. and McLean, M. (2007), "Tripartite assessment of learners during practice placments in midwifery pre-registration programmes", Education + Training, Vol. 49 No.3, pp.227-35. 
Ekebergh, M., Lepp, M. and Dahlberg, K. (2004), "Reflective learning with drama in nursing education-a Swedish attempt to overcome the theory practice gap", Nurse Education Today, Vol. 24 No.1, pp.622-28.

Emad, G. and Roth, W.-M. (2008), “Contradictions in practices of training for and assessment of competency: a case study from the maritime domain", Education + Training, Vol. 50 No.3, pp.260-72.

Emad, G. and Roth, W.-M. (2009), "Policy as boundary object: A new way to look at educational policy design and implementation", Vocations and Learning, Vol. 2 No.1, pp.19-35.

Engeström, Y. (2000), "Activity theory as a framework for analyzing and redesigning work", Ergonomics, Vol. 43 No.7, pp.960-974.

Engeström, Y., Virkkunen, J., Helle, M., Pihlaja, J. \& Poikela, R. (1996). Change laboratory as a tool for transforming work. Lifelong Learning in Europe, Vol. 1 No.2), pp.10-17.

Goody, E.N. (1989), "Learning, apprenticeship and the division of labor", in M.W. Coy (Ed.), Apprenticeship: From Theory to Method and Back Again, State University of New York Press, Albany, NY, pp.233-56.

Jahreie, C.F. (2012), "Learning to teach at the boundaries between university courses and internships", Acta Didactica Norge, Vol. 6 No.1. Accessed October 12, 2012 at http://adno.no/index.php/adno/article/view/213

Heidegger, M. (1977), Sein und Zeit [Being and Time], Max Niemeyer, Tübingen, Germany.

Hutchins, E. (1995), Cognition in the Wild, MIT Press, Cambridge, MA.

Lave, J. (1993), “The practice of learning”, in Chaiklin, S. and Lave, J. (Eds.), Understanding Practice: Perspectives on Activity and Context, Cambridge University Press, Cambridge, UK, pp.3-32.

Lave, J. (1996), Teaching, as learning, in practice", Mind, Culture, and Activity, Vol. 3 No.3, 149-164.

Leont'ev, A.N. (1983), Dejatel'nost'. Soznanie. Ličnost'. [Activity, consciousness, personality], in Izbrannye psixhologičeskie proizvedenija vol. 2, Pedagogika, Moscow, Russia, pp.94-231.

Livingston, E. (1986), The Ethnomethodological Foundations of Mathematics, Routledge and Kegan Paul, London, UK.

Lukács, G. (1971), History and Class Consciousness: Studies in Marxist Dialectics, Merlin Press, London, UK.

Marx, K./Engels, F. (1958), Werke Band 3 [Works vol. 3] , Dietz, Berlin, Germany. Marx, K./Engels, F. (1961), Werke Band 13 [Works vol. 13] , Dietz, Berlin, Germany. Mavin, T.J. and Murray, P. (2010), "The development of airline pilot skills through practice", in Billett, S. (Ed.), Learning through Practice: Models, Traditions, Orientations and Approaches, Springer, Dordrecht, The Netherlands, pp.268-86.

Merz, M. and Knorr-Cetina, K. (1997), "Deconstruction in a 'thinking' science: Theoretical physicists at work", Social Studies of Science, Vol. 27 No.1, pp.73-111. Moje, E.B. (2004), "Powerful spaces: Tracing the out-of-school literacy spaces of Latino/a youth", in Leander, K. and Sheehy, M. (Eds.), Space Matters: Assertions of Space in Literacy Practice and Research, Peter Lang, New York, NY, pp.15-38. 
Nematollahi, R. and Isaac, J.P. (2012), "Bridging the theory practice gap: A review of graduate nurse program (GNP) in Dubai, United Arab Emirates", International Nursing Review, Vol. 59 No.2, pp.194-99.

Noss, R. and Hoyles, C. (1996), "The visibility of meanings: Modelling the mathematics of banking", International Journal of Computers for Mathematical Learning, Vol. 1 No.1, 3-31.

O’Flaherty, J., Liddy, M., Tansey, L. and Roche, C. (2011), “Educating engaged citizens: Four projects from Ireland", Education + Training, Vol. 53 No.4, pp.26783.

Patel, N., Brinkman, W.-P. and Coughlan, J. (2012), "Workplacements and academic achievement: Undergraduate computing students", Education + Training, Vol. 54 No.6, pp. 523-33.

Racca, R.L. (2003), Crossed Wires: Challenges to Traditional Apprenticeship in the Electrical Trade (Unpublished master's thesis), University of Victoria, Victoria, BC, Canada.

Ricœur, P. (1992), Oneself as Another, University of Chicago Press, Chicago, IL.

Roth, W.-M. (2004), "Activity theory in education: An introduction", Mind, Culture, \& Activity, Vol. 11 No.1, pp.1-8.

Roth, W.-M. (2005), Doing Qualitative Research: Praxis of Methods, Sense Publishers, Rotterdam, The Netherlands.

Roth, W.-M. (2007a), "Emotion at work: A contribution to third-generation cultural historical activity theory", Mind, Culture and Activity, Vol. 14 No.1, 40-63.

Roth, W.-M. (2007b), "Epistemic mediation: Video data as filters for the objectification of teaching by teachers", in: Goldman, R., Pea, R., Barron, B., and Derry, S. (Eds.), Video Research in the Learning Sciences, Lawrence Erlbaum Associates, . Mahwah, NJ, pp. 367-82.

Roth, W.-M. (2010), "Martin Heidegger comes to the support of CHAT researchers", Mind, Culture, and Activity, Vol. 17 No.1, pp.1-10.

Roth, W.-M. (2012), "Rules of bending, bending the rules: The geometry of conduit bending in college and workplace", Educational Studies in Mathematics. DOI: 10.1007/s10649-011-9376-4

Roth, W.-M. (2013), "Reading Activity, Consciousness, Personality dialectically: Cultural-historical activity theory and the centrality of society", Mind, Culture and Activity, Vol. 13 No.?, ???-???. DOI: 10.1080/10749039.2013.771368

Roth, W.-M. and Lee, Y.J. (2007), “'Vygotsky's neglected legacy': Cultural-historical activity theory", Review of Educational Research, Vol. 77 No.2, pp.186-232.

Roth, W.-M. and Tobin, K. (2002), “Redesigning an 'urban' teacher education program: An activity theory perspective”, Mind, Culture, \& Activity, Vol. 9 No.2, pp.108-31.

Roth, W.-M., Tobin, K., Zimmermann, A., Bryant, N. and Davis, C. (2002), “Lessons on/from the dihybrid cross: An activity theoretical study of learning in coteaching", Journal of Research in Science Teaching, Vol. 39 No.3, pp.253-82.

Schön, D.A. (1983), The Reflective Practitioner: How Professionals Think in Action, Basic Books, New York, NY. 
Tsui, A.B.M. and Law, D.Y.K. (2007), "Learning as boundary-crossing in a schooluniversity partnership", Teachers and Teacher Education, Vol. 23 No.8, 12891301.

Vygotskij, L.S. (2005), Psixhologija Razvitija Čeloveka [Psychology of Human Development] , Eksmo, Moscow, Russia.

Vygotsky, L.S. (1927/1997), "The historical meaning of the crisis in psychology: A methodological investigation", in Rieber, W.R. and Wollock, J. (Eds.), The collected work of L. S. Vygotsky vol. 6, Kluwer Academic / Plenum Publishers, New York, NY, pp.233-343.

Zhang, M., Lundeberg, M, Koehler, M. J. and Eberhardt, J. (2011), “Understanding affordances and challenges of three types of video for teacher professional development", Teaching and Teacher Education, Vol. 27 No.2, 454-62. 
Table 1. Excerpt from the evaluation metric used by the airline

\begin{tabular}{|c|c|c|c|c|}
\hline & 1 & 2 & 3 & 4 \\
\hline $\begin{array}{l}\text { Situation Awareness } \\
\text { - perception } \\
\text { - comprehension } \\
\text { - projection }\end{array}$ & $\begin{array}{l}\text { - Lacked awareness of } \\
\text { clearly obvious systems } \\
\text { or environmental factors. } \\
\text { - Misinterpreted or did not } \\
\text { comprehend factors } \\
\text { affecting flight safety. } \\
\text { - Did not predict future } \\
\text { events, even those } \\
\text { obvious to flight safety. }\end{array}$ & $\begin{array}{l}\text { - Missed some minor } \\
\text { systems or } \\
\text { environmental factors } \\
\text { not critical to flight } \\
\text { safety. } \\
\text { - Comprehended some } \\
\text { factors and implication } \\
\text { on flight safety. } \\
\text { - Difficulty predicting } \\
\text { future events. }\end{array}$ & $\begin{array}{l}\text { - Perceived significant } \\
\text { systems or } \\
\text { environmental factors } \\
\text { affecting flight. } \\
\text { - Comprehended } \\
\text { significant factors and } \\
\text { implication on flight } \\
\text { safety with few errors. } \\
\text { - Some difficulty predicting } \\
\text { future events. }\end{array}$ & $\begin{array}{l}\text { - Perceived all systems } \\
\text { or environmental } \\
\text { factors affecting flight. } \\
\text { - Comprehended the } \\
\text { implication of all } \\
\text { factors } \\
\text { - Predicted future } \\
\text { events and impact on } \\
\text { flight safety }\end{array}$ \\
\hline $\begin{array}{l}\text { Communication } \\
\text { - Clear and correct } \\
\text { - Information flow } \\
\text { - Timeliness }\end{array}$ & $\begin{array}{l}\text { - Unclear and incorrect } \\
\text { - Blocked inputs or } \\
\text { withheld information } \\
\text { - Timing created confusion } \\
\text { or misunderstanding }\end{array}$ & $\begin{array}{l}\text { - Occasionally unclear and } \\
\text { incorrect } \\
\text { - Resistant to inputs or } \\
\text { limited participation } \\
\text { - Poorly timed }\end{array}$ & $\begin{array}{l}\text { - Clear and correct, with } \\
\text { only minor mistakes } \\
\text { - Mostly receptive to crew } \\
\text { inputs; adequate } \\
\text { participation } \\
\text { - Adequately timed }\end{array}$ & $\begin{array}{l}\text { - Clear and correct } \\
\text { - Receptive to other crew } \\
\text { members' inputs, whilst } \\
\text { own contribution well } \\
\text { considered } \\
\text { - Timely }\end{array}$ \\
\hline
\end{tabular}


Table 2. Typical flight scenario

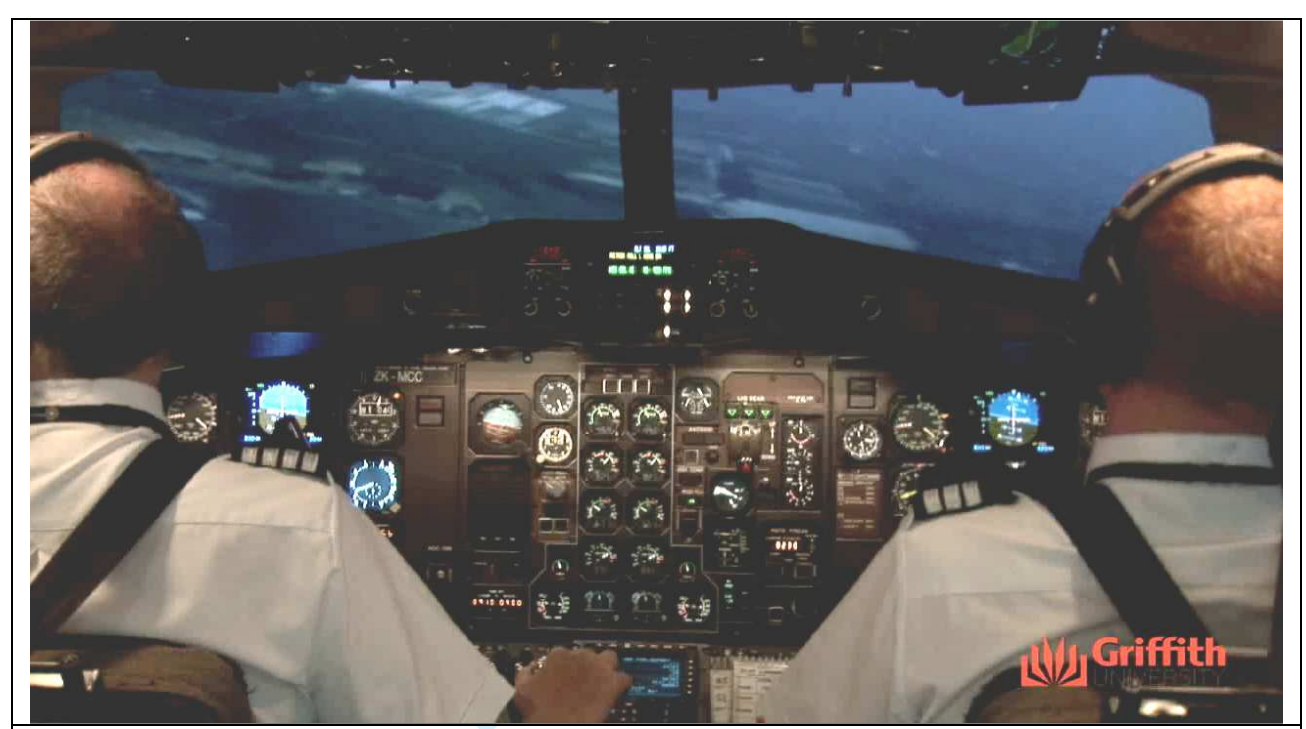

Scenario: The captain (flying pilot) and first officer conduct an instrument-based approach by day. When they come close to the airport, they become visual (photo). During visual maneuvering, and just as they make the final turn to align with the runway, the aircraft encounters rain. The crew decides to enact the "missed approach procedure," which means that they return to higher altitude prior to attempting another approach or to fly to another airport. During this procedure, the captain initially turns the plane into the wrong direction (towards the mountains, but this was immediately corrected by the first officer. 
a.

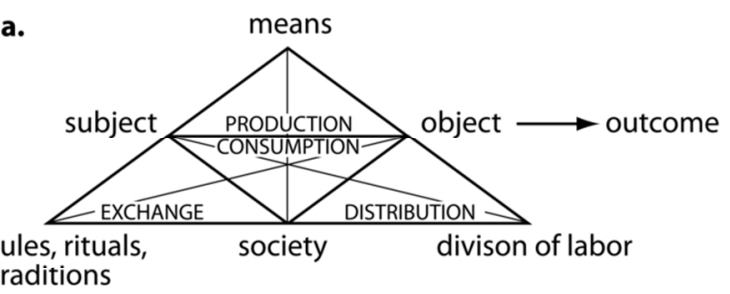
trasing b.

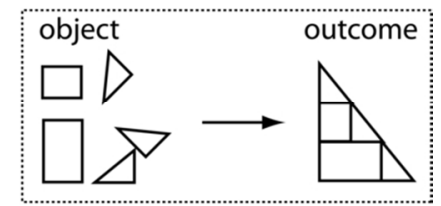

Figure 1. a. The structural unit of analysis of cultural-historical activity theory. b. The temporal unit of analysis includes starting objects, final product, and all actions required to transform the former into the latter.

$50 \times 15 \mathrm{~mm}(600 \times 600 \mathrm{DPI})$ 
Figure 2. A pair of pilots (researcher on the right) is in the process of assessing the performance of a crew on the simulator using the same metric that is used for their semi-annual praxis-based evaluation (on the simulator).

$127 \times 95 \mathrm{~mm}(300 \times 300 \mathrm{DPI})$

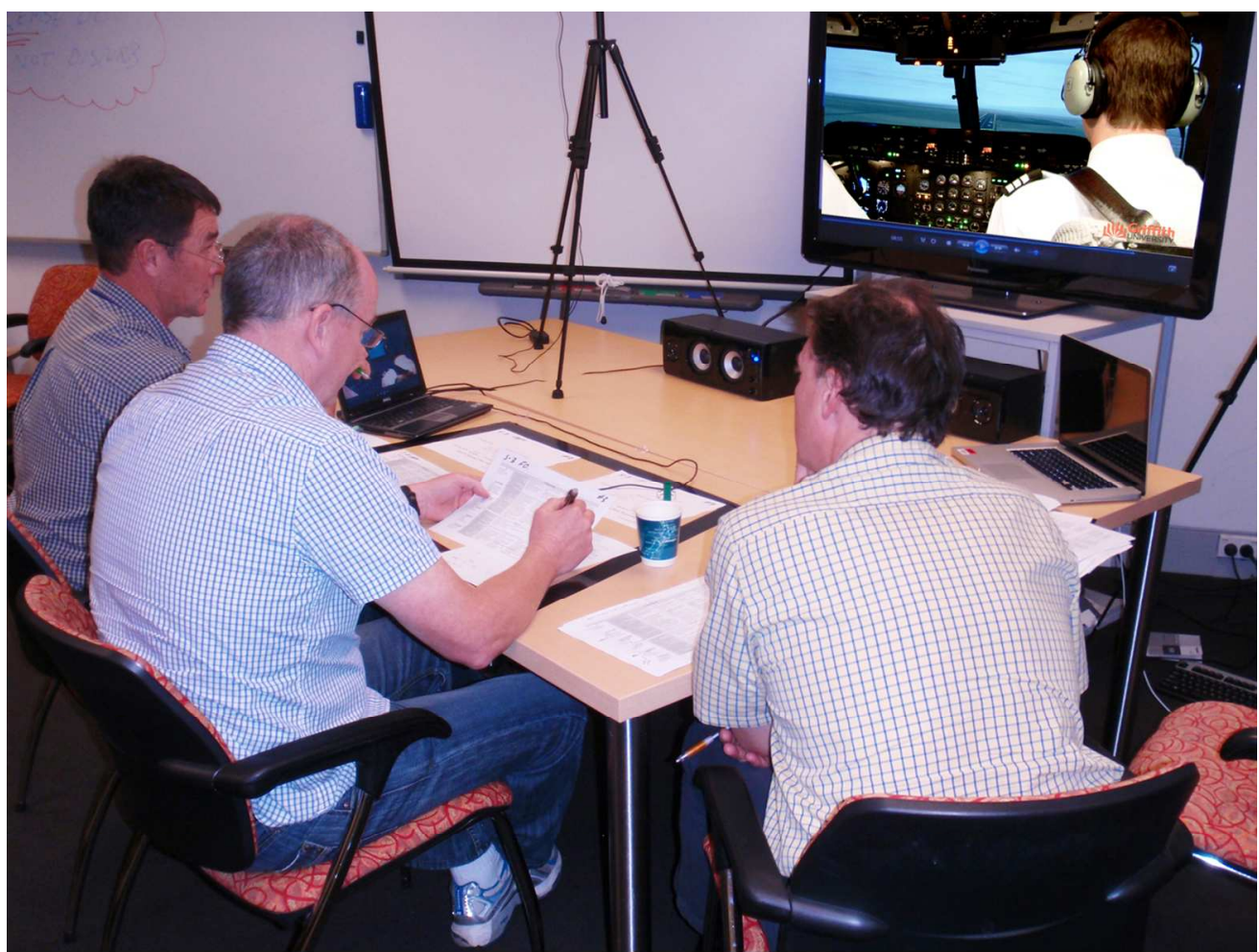

